\title{
Peptide-based inhibition of I $\kappa B$ kinase/nuclear factor- $\kappa B$ pathway protects against diabetes-associated nephropathy and atherosclerosis in a mouse model of type 1 diabetes
}

\author{
Ainhoa Oguiza ${ }^{1,2,3}$ - Carlota Recio ${ }^{1,2,3}$ - Iolanda Lazaro ${ }^{1,2}$ • Beñat Mallavia ${ }^{1,2}$. \\ Julia Blanco $^{4}$ • Jesus Egido ${ }^{2,3}$ - Carmen Gomez-Guerrero ${ }^{1,2,3}$
}

Received: 29 November 2014 / Accepted: 7 April 2015 /Published online: 28 April 2015

(C) Springer-Verlag Berlin Heidelberg 2015

\begin{abstract}
Aims/hypothesis The canonical nuclear factor- $\mathrm{kB}(\mathrm{NF}-\mathrm{kB})$ pathway mediated by the inhibitor of NF-KB kinase (IKK) regulates the transcription of inflammatory genes involved in the pathogenesis of diabetes, from the early phase to progression and final complications. The NF- $\mathrm{kB}$ essential modulator binding domain (NBD) contained in IKK $\alpha / \beta$ is essential for IKK complex assembly. We therefore investigated the functional consequences of targeting the IKK-dependent NF- $\mathrm{KB}$ pathway in the progression of diabetes-associated nephropathy and atherosclerosis.

Methods Apolipoprotein E-deficient mice with diabetes induced by streptozotocin were treated with a cell-permeable peptide derived from the IKK $\alpha / \beta$ NBD region. Kidneys and aorta were analysed for morphology, leucocyte infiltrate, collagen, NF-KB activity and gene expression. In vitro studies were performed in renal and vascular cells.

Results NBD peptide administration did not affect the metabolic severity of diabetes but resulted in renal protection, as
\end{abstract}

Carmen Gomez-Guerrero

cgomez@fjd.es

1 Renal and Vascular Inflammation Group, IIS-Fundacion Jimenez Diaz, Autonoma University of Madrid, Avda. Reyes Catolicos, 2, 28040 Madrid, Spain

2 Nephrology Department, IIS-Fundacion Jimenez Diaz, Autonoma University of Madrid, Madrid, Spain

3 Spanish Biomedical Research Centre in Diabetes and Associated Metabolic Disorders (CIBERDEM), Spain,

http://www.ciberdem.org

4 Department of Pathology, Hospital Clinico San Carlos, Madrid, Spain evidenced by dose-dependent decreases in albuminuria, renal lesions (mesangial expansion, leucocyte infiltration and fibrosis), intranuclear NF-KB activity and proinflammatory and pro-fibrotic gene expression. Furthermore, peptide treatment limited atheroma plaque formation in diabetic mice by decreasing the content of lipids, leucocytes and cytokines and increasing plaque stability markers. This nephroprotective and anti-atherosclerotic effect was accompanied by a decline in systemic $T$ helper 1 cytokines. In vitro, NBD peptide prevented IKK assembly/activation, p65 nuclear translocation, NF-kB-regulated gene expression and cell proliferation induced by either high glucose or inflammatory stimulation. Conclusions/interpretation Peptide-based inhibition of IKK complex formation attenuates NF- $\mathrm{KB}$ activation, suppresses inflammation and retards the progression of renal and vascular injury in diabetic mice, thus providing a feasible approach against diabetes inflammatory complications.

Keywords Atherosclerosis - Diabetes - Inflammation · Nephropathy $\cdot$ Nuclear factor-kB $\cdot$ Peptide

$\begin{array}{ll}\text { Abbreviations } \\ \text { ApoE } & \text { Apolipoprotein E } \\ \text { CCL } & \text { C-C chemokine ligand } \\ \text { HG } & \text { High glucose } \\ \text { IKK } & \text { Inhibitor of NF-kB (IKB) kinase } \\ \text { LPS } & \text { Lipopolysaccharide } \\ \text { MC } & \text { Mesangial cells } \\ \text { MOMA-2 } & \text { Monocyte/macrophage marker 2 } \\ \text { NBD } & \text { NF- } k \text { B essential modulator (NEMO) } \\ & \text { binding domain } \\ \text { NEMO } & \text { NF- } k B \text { essential modulator } \\ \text { NF- } K B & \text { Nuclear factor- } k B \\ \text { PAS } & \text { Periodic acid-Schiff }\end{array}$


Th

VSMC

T helper

Vascular smooth muscle cells

\section{Introduction}

Diabetes mellitus is a disease of metabolic dysregulation, characterised by hyperglycaemia and the development of diabetes-specific pathology. Complications affecting the macrovasculature and microvasculature are the major causes of morbidity and mortality among diabetic patients [1]. Diabetic nephropathy, which largely contributes to end-stage renal disease, is an important risk factor for macrovascular disease, while atherosclerosis is the main reason for impaired life expectancy in diabetic patients [2, 3]. Hyperglycaemia, hyperlipidaemia and chronic inflammation are involved in the clinically well-recognised complications of diabetes. In fact, released inflammatory cytokines and chemokines contribute to atherosclerotic plaque formation, while growth factors and adhesion molecules promote inflammatory cell recruitment into the renal microvasculature, predisposing patients to diabetic nephropathy development $[4,5]$.

The nuclear factor- $\mathrm{kB}$ (NF-kB) intracellular pathway controls numerous biological processes and its activation has been linked to many pathological conditions including inflammatory diseases $[6,7]$. The canonical pathway of NF- $\mathrm{kB}$ activation downstream of pro-inflammatory stimuli (e.g. TNF $\alpha$, IL1 and bacterial endotoxin) is mediated by the inhibitor of NF- $k B$ (IKB) kinase (IKK) complex, which phosphorylates the inhibitory $\operatorname{I} \kappa \mathrm{B} \alpha$ protein to induce its polyubiquitination and proteasome-mediated degradation. Thus, NF-kB subunits (predominantly the p65-p50 heterodimer) are released and translocated to the nucleus where they regulate inflammatory gene transcription $[6,7]$. The IKK complex is formed by two catalytic subunits (IKK $\alpha$ and IKK $\beta$ ) and the regulatory subunit (NF-KB essential modulator [NEMO]) [8]. IKK $\alpha$ and IKK $\beta$ share significant homology and contain an N-terminal kinase domain, a central ubiquitin-like domain and an elongated $\alpha$-helical scaffold/dimerisation domain followed by a NEMO-binding domain (NBD; Fig. 1a) [9]. IKK $\alpha / \beta$ kinase activity critically depends on the phosphorylation of two serine residues located in the activation loop [9], while the NBD region contained in the $\mathrm{C}$-terminus of IKK $\alpha$ (L738-L743) and IKK $\beta$ (L737 and L742) is essential for assembly and stabilisation of the heteromeric IKK $\alpha / \beta$-NEMO complex [10].

Clinical and experimental evidence implicates NF-KB activation and regulated genes in the early phases, progression and final complications of diabetes and, as such, its inhibition offers therapeutic intervention opportunities [11-17]. Although several NF-KB inhibitors have reached phase II/III clinical trials for inflammatory diseases $[18,19]$, most research into cardiovascular or renal diseases is only in the
Fig. 1 NBD peptide inhibits IKK/NF- $k B$ activation in vitro. (a) Domain structure of IKK $\beta$ protein (KD, kinase domain; ULD, ubiquitin-like domain; SDD, scaffold/dimerisation domain); the sequence of residues $701-745$ containing the NBD region is underlined, and the sequence of synthetic cell-permeable NBD and mutant ( red, $\mathrm{W} \rightarrow \mathrm{A}$ ) peptides is shown. (b) Fluorescence images ( $n=3$ experiments) showing cytosolic distribution of rhodamine-NBD peptide $(2 \mu \mathrm{mol} / \mathrm{l})$ in VSMC over time. (c) Confocal images ( $n=4$ experiments) of NBD peptide and p65 NF- $\mathrm{kB}$ subunit localisation in MCT and VSMC after $60 \mathrm{~min}$ of HG stimulation. (d-f) Western blot analysis of 655 protein (loading control, histone $\mathrm{H} 3$ ) in nuclear extracts from MC (d, e) and VSMC (f) treated with peptides ( $2 \mu \mathrm{mol} / 1,90 \mathrm{~min}$ ) before stimulation (HG, $60 \mathrm{~min}$; LPS, $30 \mathrm{~min}$ ). (g) DNA-binding ELISA assay to quantify NF- $\mathrm{kB}$ activation in nuclear extracts from MC and VSMC. (h) Immunoprecipitation of NEMO with $\mathrm{IKK} \alpha / \beta$ subunits in MC. (i) Immunodetection of $\operatorname{IKK} \alpha / \beta$ phosphorylation (Ser176/180) in MC. Representative immunoblots and summary of normalised densitometric quantification are shown. Results expressed as relative increases over basal (arbitrarily set to 1) are means \pm SEM of 3-5 independent experiments each performed in duplicate assays. White bars represent basal; diagonal-striped bars, basal+NBD; black bars, stimulus; grey bars, NBD+stimulus; horizontal-striped bars, mutant + stimulus. ${ }^{*} p<0.05$ vs basal; ${ }^{\dagger} p<0.05$ vs stimulus. IP, immunoprecipitate; Mut, mutant

preliminary experimental phase [20]. This work investigates whether IKK-targeted NF-KB inhibition improves diabetic complications. To that end, the nephroprotective and antiatherosclerotic properties of a cell-permeable peptide spanning the IKK $\alpha / \beta$ NBD region (in order to disrupt IKK $\alpha / \beta$ NEMO interactions) were analysed in a mouse model of diabetes and in cells under hyperglycaemic/inflammatory stimulation.

\section{Methods}

Peptide synthesis Peptides derived from the IKK $\beta$ NBD region (TALDWSWLQTE; mutant $\mathrm{W} \rightarrow$ A; Fig. 1a) were synthesised in tandem with a cationic cell-penetrating peptide (octalysine; ProteoGenix, Schiltigheim, France), and rhodamine-conjugated, dissolved and filter sterilised.

In vitro studies Primary mouse mesangial cells (MC), vascular smooth muscle cells (VSMC) and a proximal tubuloepithelial cell line (MCT) were cultured in medium containing 10\% FCS (Life Technologies, Rockville, MD, USA) [21-24]. Quiescent cells were treated for 90 min with peptides before short-term incubation with high glucose (HG; $30 \mathrm{mmol} / \mathrm{l} \mathrm{D}$-glucose, $60 \mathrm{~min}$ ) or lipopolysaccharide (LPS; $1 \mu \mathrm{g} / \mathrm{ml}, 30 \mathrm{~min}$; Sigma-Aldrich, St Louis, MO, USA). $\mathrm{NF}-\mathrm{KB}$ activation was assessed by immunofluorescence and immunoprecipitation/western blot using antibodies against p65 (Santa Cruz Biotechnology, Santa Cruz, CA, USA), NEMO (BD Biosciences, Erembodegem, Belgium), IKK $\alpha / \beta$, phospho-IKK $\alpha / \beta$ and histone H3 (Cell Signaling Technology, Danvers, MA, USA). NF-KB DNA-binding activity was assessed by an ELISA-based assay (Active Motif, 

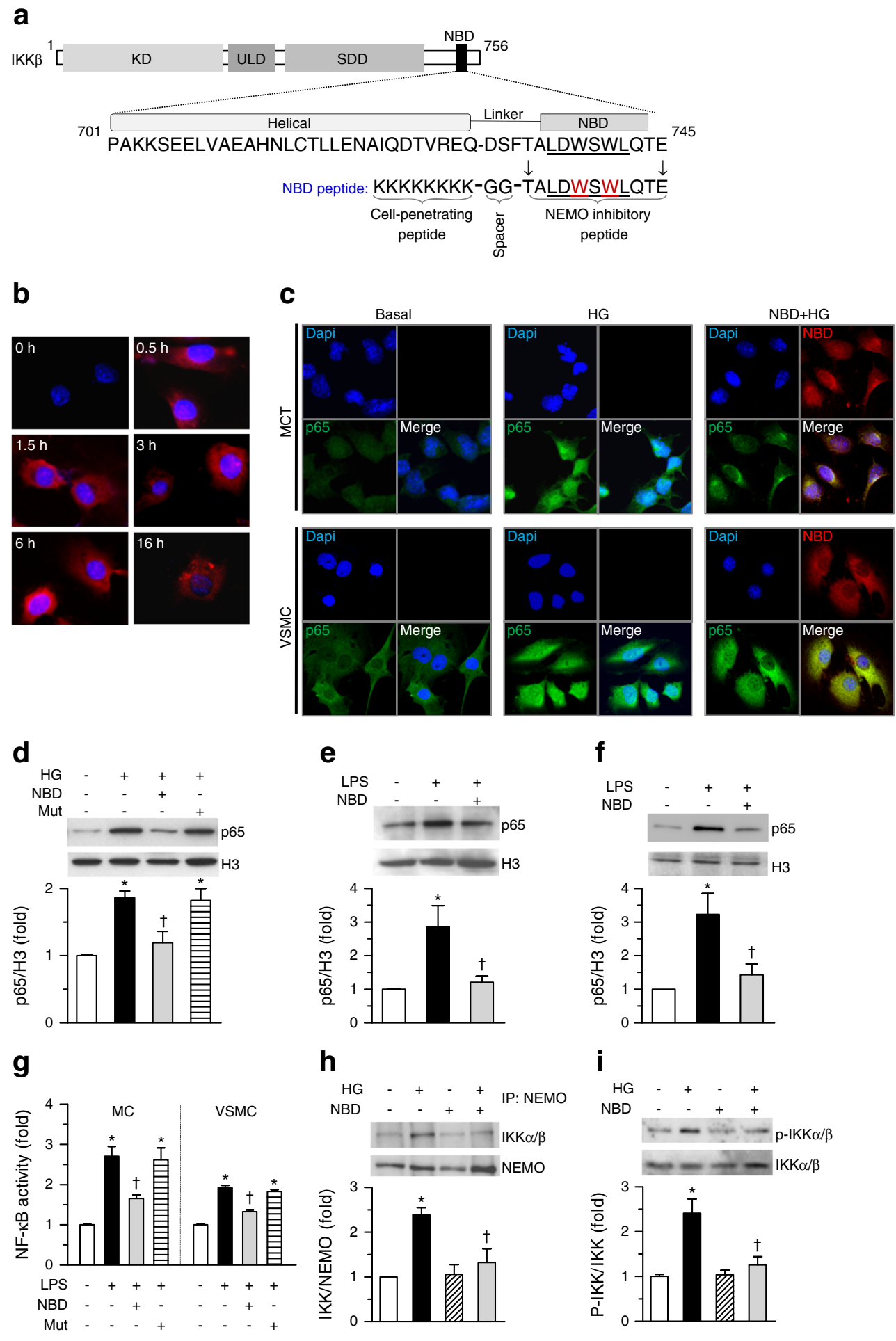

Carlsbad, CA, USA). Gene expression after long-term co-incubation of peptide with HG and LPS was analysed by realtime quantitative PCR (Applied Biosystems, Foster City, CA, USA). C-C chemokine ligand 2 (CCL2) levels were measured by ELISA (BD Biosciences). For cell proliferation studies, cells were maintained for $48 \mathrm{~h}$ in medium containing low glucose $(5 \mathrm{mmol} / \mathrm{l})$ or $\mathrm{HG}(30 \mathrm{mmol} / \mathrm{l})$ and different peptide concentrations, and then assessed by a tetrazolium dye colorimetric assay.

In vivo studies Animal studies conformed to the Directive 2010/63/EU of the European Parliament and were approved by the Institutional Animal Care and Use Committee (IISFundacion Jimenez Diaz). Model type 1 diabetes was induced 
in 10-week-old male apolipoprotein E knockout $\left(\right.$ Apoe $\left.^{-/-}\right)$ mice (Jackson Laboratory, Bar Harbor, ME, USA) by streptozotocin injection (125 mg kg${ }^{-1}$, two consecutive days) $[21,24]$. Mice with overt diabetes (glycaemia $>19.4 \mathrm{mmol} / \mathrm{l}$ ) were injected i.p. with either NBD peptide $(0.7 \mu \mathrm{mol} / \mathrm{kg}, n=7$; $4 \mu \mathrm{mol} / \mathrm{kg}, n=9$; every other day) or vehicle $(0.1 \%$ acetonitrile in $200 \mu \mathrm{l}$ saline, $n=9)$ during 10 weeks. Age-matched Apoe ${ }^{-/-}$ mice (NBD $4 \mu \mathrm{mol} / \mathrm{kg}, n=4$; vehicle, $n=4$ ) were used as nondiabetic controls. Ex vivo confocal microscopy studies were performed after a single dose of rhodamine-labelled peptide. At the study endpoint, $16 \mathrm{~h}$-fasted mice were anaesthetised, saline-perfused and killed, and organs were collected. Paraffin-embedded kidney sections were stained with periodic acid-Schiff (PAS) and blindly graded (0-3 scale) according to the extent of glomerular (hypertrophy, hypercellularity and mesangial expansion; 30 glomeruli per sample), tubular (atrophy and degeneration; 20 fields at $\times 40$ per sample) and interstitial (fibrosis and infiltration; 20 fields at $\times 40$ per sample) lesions [21]. Glomerular size and $\mathrm{PAS}^{+}$ mesangial area were quantified by morphometry. Atherosclerotic lesions were analysed in Oil Red $\mathrm{O} /$ haematoxylin-stained aortic root sections [23]. Immunodetection of macrophages (F4/80 and monocyte/ macrophage marker (MOMA-2); Serotec, Oxford, UK), T lymphocytes (CD3; DAKO, Glostrup, Denmark), VSMC ( $\alpha$-actin-Cy3; Sigma-Aldrich), CCL2 (Peprotech, Rocky Hill, NJ, USA), CCL5 (Antibodies-online, Aachen, Germany) and TNF $\alpha$ (Santa Cruz Biotechnology) was performed by immunoperoxidase/immunofluorescence. Collagen was examined by picrosirius red staining. Activated NF- $\mathrm{kB}$ was assessed by in situ south-western histochemistry $[23,25]$. Positive staining (two to three tissue slices/mouse) was expressed as percentage of total area and number of cells (per glomerulus or $\mathrm{mm}^{2}$ ). Gene expression was analysed by real-time quantitative PCR and normalised to housekeeping $18 \mathrm{~S}$. Serum lipids and transaminases were measured by automated methods, blood $\mathrm{HbA}_{1 \mathrm{c}}$ and urine albumin by ELISA (Gentaur, Kampenhout, Belgium; Cell Trend, Luckenwalde, Germany) and creatinine by enzymatic assay (Abcam, Cambridge, UK).

Statistics Data shown are the means \pm SEM of determinations in duplicate/triplicate per group. Differences across groups were considered significant at $p<0.05$ (two-way ANOVA with Bonferroni's post hoc test).

\section{Results}

Inhibition of the NF- $\mathrm{B}$ pathway and cellular responses by NBD peptide in vitro Fluorescence microscopy in VSMC (Fig. 1b) and MCT (not shown) revealed a time-dependent delivery of cell-permeable rhodamine-conjugated NBD peptide that was homogeneously distributed in the cytoplasm. Further co-localisation experiments demonstrated that NBD inhibits the nuclear translocation of the p65 subunit in MCT and VSMC after short-term HG incubation (Fig. 1c). NBD also significantly reduced $\mathrm{p} 65$ content (Fig. $1 \mathrm{~d}-\mathrm{f}$ ) and DNAbinding activity (Fig. 1g) in nuclear extracts from MC and VSMC stimulated with either HG or LPS. Further immunoprecipitation/western blot studies confirmed that NBD peptide disrupts the interaction of NEMO with IKK $\alpha / \beta$ subunits in HG-stimulated MC without affecting basal levels (Fig. 1h), and also prevents IKK $\alpha / \beta$ phosphorylation (Fig. 1i). Real-time PCR revealed a dose-dependent inhibition of NF-kB-dependent genes $(\mathrm{Ccl} 2, \mathrm{Ccl} 5$ and $\operatorname{Tnf} \alpha)$ by the NBD peptide in HG-stimulated MCT (Fig. 2a, b), with an inhibition efficiency $\left(\mathrm{IC}_{50}=2.1-3.4 \mu \mathrm{mol} / \mathrm{l}\right)$ in a similar micromolar range as previously tested $[10,26]$. In MC, NBD peptide decreased pro-inflammatory gene expression induced by HG and LPS stimulation (Fig. 2c, d) and also attenuated CCL2 chemokine secretion (ng/ml: basal $6 \mathrm{~h}$ $0.6 \pm 0.1 ; \mathrm{HG} 6.9 \pm 2.0 ; \mathrm{NBD}+\mathrm{HG} 0.7 \pm 0.2, p=0.03$ vs HG; $n=4$ ). Sustained inhibition (up to $24 \mathrm{~h}$ exposure) was also observed in HG-stimulated VSMC (Fig. 2e). Remarkably, NBD peptide did not influence cell viability, but it was able to inhibit, in a dose-dependent manner, the proliferation of MC induced by long-term exposure to $\mathrm{HG}$ (Fig. 2f). In all these experiments, no significant effects were observed with mutant peptide (Figs 1,2).

NBD peptide treatment protects mice from diabetic renal injury The therapeutic potential of IKK-targeted NF- $\mathrm{KB}$ inhibition was evaluated in diabetic $A p o e^{-/-}$mice, an experimental model of combined hyperglycaemia and hyperlipidaemia that accelerates nephropathy and atherosclerosis development $[21,27]$. Fluorescence experiments revealed efficient accumulation of rhodamine-peptide in mouse tissues (Fig. 3a). Subsequently, we analysed the evolution of diabetic mice and non-diabetic controls treated with either vehicle or NBD peptide at two different doses $(0.7$ and $4 \mu \mathrm{mol} / \mathrm{kg})$ for a period of 10 weeks. Peptide administration had no significant effect on hyperglycaemia, body weight and serum lipid profile in diabetic mice (Table 1). Throughout the study, neither overt toxicity or lethality, nor hepatic or splenic damage were observed in NBD-treated groups (not shown). Serum transaminase activities were also similar across the groups (Table 1), indicating preserved liver function. Remarkably, NBD treatment dose-dependently improved renal function in diabetic mice, as evidenced by significant reductions of serum creatinine, urine albumin-to-creatinine and kidney-to-body weight ratios (Table 1).

Histological analysis of PAS-stained renal samples (Fig. 3b, c; Table 1) revealed that NBD peptide ameliorated the following pathologic changes associated with diabetes: (1) glomerular hypertrophy, hypercellularity and mesangial 

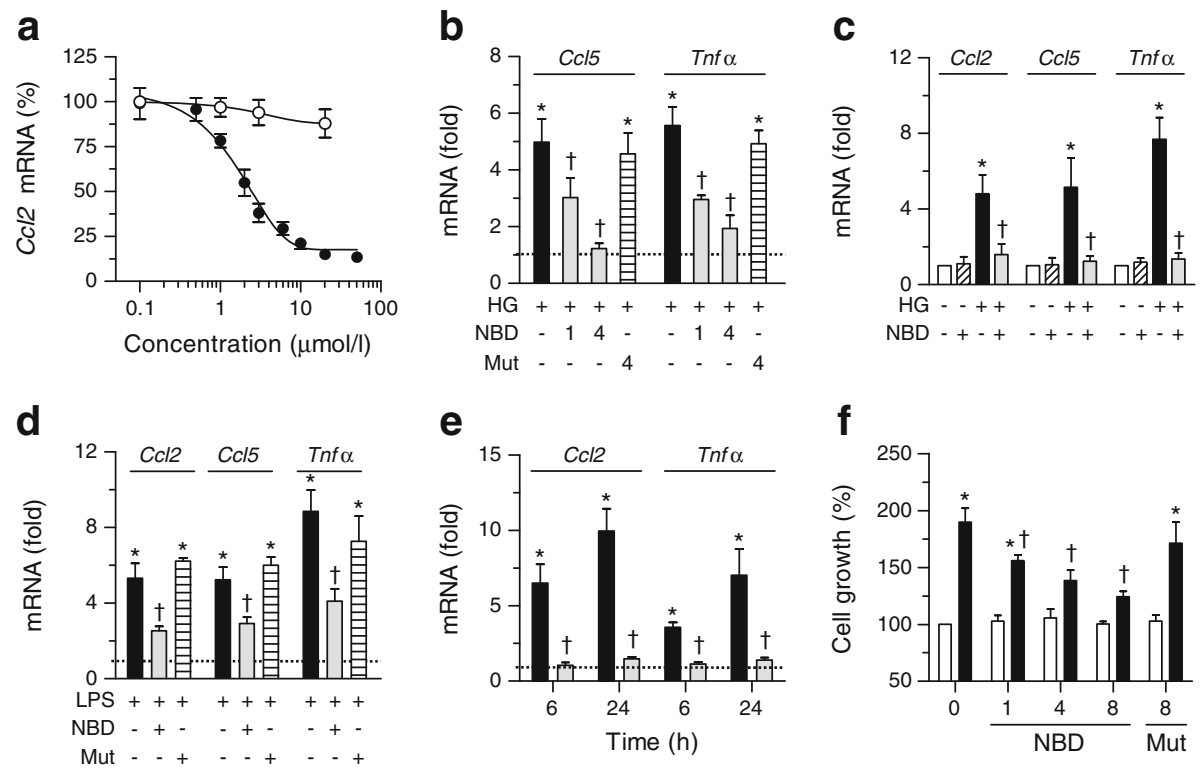

Fig. 2 NBD peptide inhibits NF-kB-regulated genes and cell proliferation. (a) Dose-response curves of peptides (NBD, black circles; mutant, white circles) on $C c l 2$ mRNA expression in HG-stimulated MCT. (b) $C c l 5$ and $\operatorname{Tnf} \alpha$ expression in MCT exposed to $\mathrm{HG}$ for $24 \mathrm{~h}$ in the presence of different peptide concentrations $(\mu \mathrm{mol} / \mathrm{l})$. (c, d) Effect of peptides $(2 \mu \mathrm{mol} / \mathrm{l})$ on proinflammatory gene expression by MC at $6 \mathrm{~h}$ of stimulation with HG (c) and LPS (d). (e) Time course of gene expression in HG-stimulated VSMC. Real-time PCR values normalised by $18 \mathrm{~S}$ are expressed as percentage vs stimulus (a) and fold increase vs basal (arbitrarily set to $1 ; \mathbf{b}-\mathbf{e})$. (f) Effect of peptide co-incubation on MC proliferation at $48 \mathrm{~h}$ under normo- and hyperglycaemic conditions. Horizontal dotted lines $(\mathbf{b}, \mathbf{d}, \mathbf{e})$ and white bars $(\mathbf{c}, \mathbf{f})$ represent basal; diagonal-striped bars, basal+NBD; black bars, stimulus; grey bars, NBD+stimulus; horizontal-striped bars, mutant + stimulus. Means \pm SEM of duplicate/triplicate determinations from 4-6 independent experiments. ${ }^{*} p<0.05 \mathrm{vs}$ basal; ${ }^{\dagger} p<0.05$ vs stimulus. Mut, mutant matrix expansion; (2) tubular atrophy, dilation and deposits of glycogen; and (3) interstitial fibrosis and inflammatory infiltrate. Picrosirius red staining (Fig. 3b, d) also demonstrated reduced renal fibrosis in NBD-treated mice. A non-significant effect of NBD peptide was observed in the renal samples from non-diabetic groups (Fig. 3b-d). Real-time PCR analysis in diabetic kidneys demonstrated significant decreases in the mRNA expression of the tubular damage marker kidney injury molecule-1 (Kim-1, also known as Havcrl; Fig. 3e) and pro-fibrotic genes (transforming growth factor- $\beta[\operatorname{Tg} f \beta]$, fibronectin and collagen type 1; Fig. 3 f) by NBD peptide. We also found a dose-dependent effect of NBD on diabetesassociated inflammation, as evidenced by lower infiltration of $\mathrm{F} 4 / 80^{+}$monocytes/macrophages and $\mathrm{CD}^{+} \mathrm{T}$ lymphocytes (Fig. $4 \mathrm{a}-\mathrm{c}$ ) and decreased gene expression of $\mathrm{Ccl} 2, \mathrm{Ccl} 5$ and Tnf $\alpha$ (Fig. 4d).

NBD therapy affects atherosclerotic plaque size and composition in diabetic mice Morphometric analysis (Oil Red $\mathrm{O} /$ haematoxylin staining; Fig. 5a) in serial aortic root sections from diabetic mice revealed that NBD markedly reduced the size (\% reduction vs vehicle: NBD0.7, $35 \pm 6, p<0.05$; NBD4, $45 \pm 8 ; p<0.01$ ), extension (Fig. 5b) and lipid content (Fig. 5c) of atheroma plaques. Furthermore, NBD-treated mice displayed less inflamed, more stable plaque phenotypes, characterised by decreased MOMA $-2^{+}$macrophages and
$\mathrm{CD}^{+} \mathrm{T}$ lymphocytes (Fig. 5d) and increased content of collagen and $\alpha$-actin (Fig. 5e), compared with vehicle control mice. Concurrently, NBD treatment also resulted in a dosedependent decrease in the gene and protein expression of chemokines and cytokines in the aorta of diabetic mice (Fig. 6a-c).

We further analysed the expression of $\mathrm{T}$ helper (Th) representative genes in spleen, the major source of cytokines involved in the initiation of systemic inflammation. NBD treatment reduced pro-inflammatory Th1 cytokines (IFN- $\gamma$, IL-12 and TNF $\alpha$ ), but not anti-inflammatory Th2 cytokines (IL-4 and IL-10; Fig. 6d), suggesting a systemically protective effect.

In vivo treatment with NBD peptide effectively blocks diabetes-induced NF- $\kappa$ B activation NF- $\mathrm{KB}$ activation in diabetic mice was analysed in situ by south-western histochemistry. Diabetic kidneys displayed an intense nuclear staining widely distributed in glomeruli and tubulointerstitium, whereas a significant decrease in the number of NF- $\mathrm{KB}^{+}$cells was observed in NBD-treated groups (Fig. 7a-c). Furthermore, NBD administration dose-dependently decreased NF- $\mathrm{KB}$ activation in atherosclerotic lesions (Fig. 7a, d). Pearson's test in the experimental groups revealed statistically significant correlations of renal NF- $\mathrm{KB}$ staining with the urine albumin-tocreatinine ratio $(r=0.515, p=0.020)$, macrophages $\left(\mathrm{F} 4 / 80^{+}\right.$: 
a

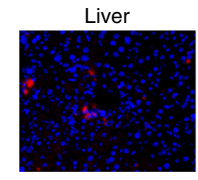

b

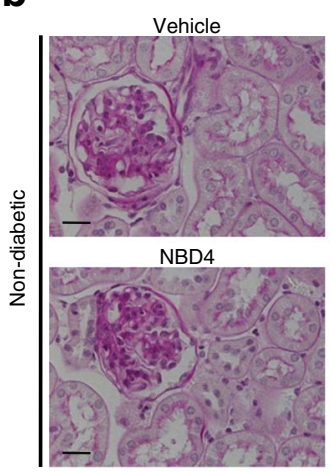

Vehicle

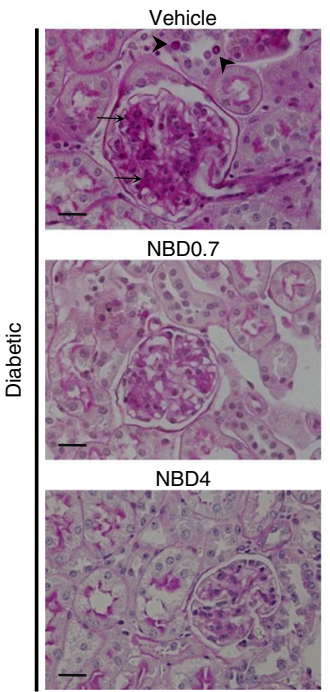

PAS
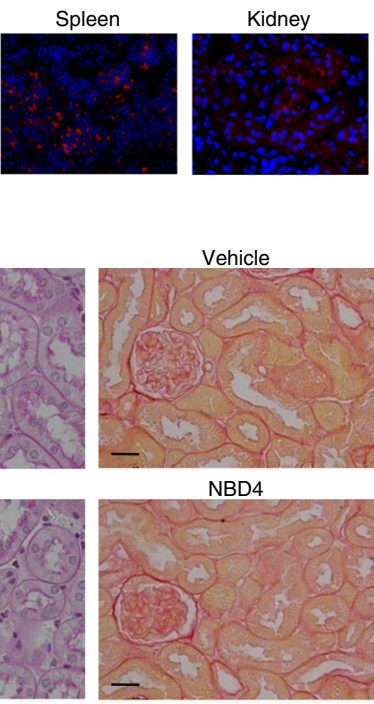

Vehicle
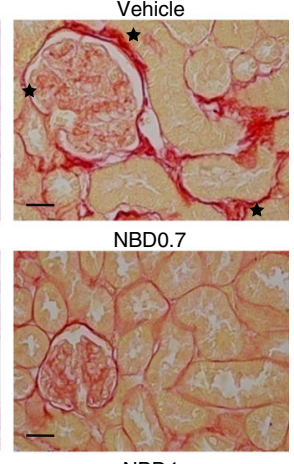

NBD4

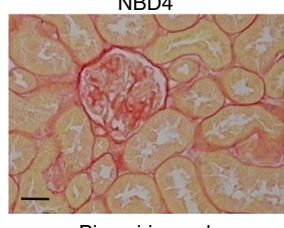

Picrosirius red

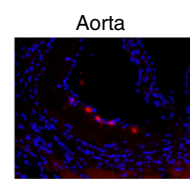

C

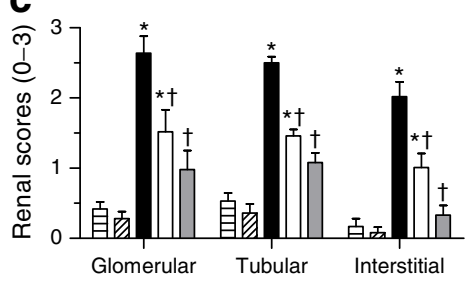

d

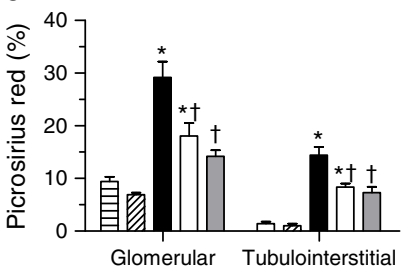

e

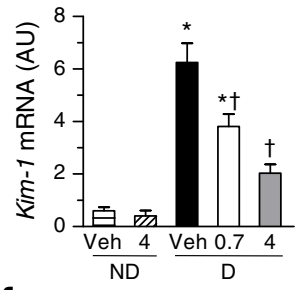

f

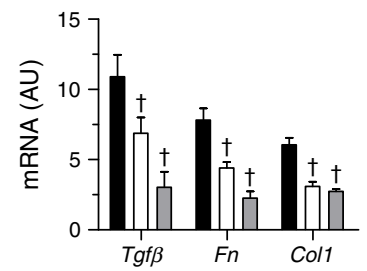

Fig. 3 NBD peptide reduces diabetes-induced renal injury in mice. (a) Ex vivo fluorescence images of mouse tissues $16 \mathrm{~h}$ after rhodamine-peptide injection (red, NBD; blue, nuclei; $n=3$ experiments). (b) Representative micrographs (scale bar, $20 \mu \mathrm{m}$ ) of PAS and picrosirius red staining in renal sections from non-diabetic and diabetic mice treated with vehicle and NBD peptide (NBD0.7 and NBD4 for 0.7 and $4 \mu \mathrm{mol} / \mathrm{kg}$, respectively) for 10 weeks. Diabetic kidneys showed glomerular hypertrophy and $\mathrm{PAS}^{+}$area expansion (arrows); tubular atrophy and glycogen deposition (arrowheads); picrosirius red $^{+}$collagen accumulation (stars). Milder damage was observed in NBD-treated diabetic mice. (c)
Semiquantitative analysis of PAS-stained tissue. (d) Collagen quantification (picrosirius red area). (e, f) Real-time PCR analysis of Kim-1, Tgf $\beta$, fibronectin $(\mathrm{Fn})$ and collagen type 1 (Coll) in renal cortex from nondiabetic (ND) and diabetic (D) mice. Normalised values are expressed in arbitrary units (AU). Data are means \pm SEM. Horizontal-striped bars indicate non-diabetic +vehicle $(n=4)$; diagonal-striped bars, nondiabetic $+\operatorname{NBD} 4(n=4)$; black bars, diabetic +vehicle $(n=9)$; white bars, diabetic+NBD0.7 $(n=7)$; grey bars, diabetic+NBD4 $(n=9)$. ${ }^{*} p<0.05$ vs non-diabetic + vehicle; ${ }^{\dagger} p<0.05$ vs diabetic + vehicle

\section{Discussion}

Nephropathy and atherosclerosis are common vascular complications in type 1 and type 2 diabetes. However, the pathogenesis of renal and vascular injury in diabetic patients has not been completely clarified, and treatments are limited and unsatisfactory $[4,5]$. This is consistent with the hypothesis that atherosclerosis. 
Table 1 Biochemical and renal variables of non-diabetic and diabetic Apoe $^{-/}$mice after 10 weeks of treatment

\begin{tabular}{|c|c|c|c|c|c|}
\hline \multirow[t]{2}{*}{ Variables } & \multicolumn{2}{|l|}{ Non-diabetic } & \multicolumn{3}{|l|}{ Diabetic } \\
\hline & Vehicle (4) & NBD4 (4) & Vehicle (9) & NBD0.7 (7) & NBD4 (9) \\
\hline$\Delta \mathrm{BW}$ (final-initial) & $2.2 \pm 0.2$ & $2.3 \pm 0.6$ & $2.2 \pm 0.4$ & $1.9 \pm 0.2$ & $1.6 \pm 0.2$ \\
\hline BG (mmol/l) & $8.9 \pm 0.4$ & $9.3 \pm 0.2$ & $29.9 \pm 0.8^{*}$ & $29.9 \pm 1.5^{*}$ & $28.9 \pm 2.0^{*}$ \\
\hline $\mathrm{HbA}_{1 \mathrm{c}}(\%)$ & ND & ND & $3.3 \pm 0.4$ & $3.3 \pm 0.3$ & $3.2 \pm 0.3$ \\
\hline $\mathrm{HbA}_{1 \mathrm{c}}(\mathrm{mmol} / \mathrm{mol})$ & ND & ND & $12.0 \pm 0.2$ & $13.0 \pm 0.1$ & $11.0 \pm 0.1$ \\
\hline Chol (mmol/1) & $8.5 \pm 0.5$ & $8.6 \pm 0.5$ & $15.6 \pm 0.4^{*}$ & $15.9 \pm 0.6^{*}$ & $16.0 \pm 1.4^{*}$ \\
\hline LDL-Chol (mmol/l) & $8.0 \pm 0.2$ & $8.3 \pm 0.1$ & $14.9 \pm 0.4^{*}$ & $14.7 \pm 1.1^{*}$ & $14.5 \pm 1.4^{*}$ \\
\hline HDL-Chol (mmol/l) & $0.34 \pm 0.03$ & $0.41 \pm 0.01$ & $0.31 \pm 0.03$ & $0.37 \pm 0.03$ & $0.28 \pm 0.02$ \\
\hline TG (mmol/l) & $0.6 \pm 0.1$ & $0.7 \pm 0.1$ & $0.9 \pm 0.1$ & $0.9 \pm 0.1$ & $0.9 \pm 0.1$ \\
\hline AST $(\mu \mathrm{kat} / \mathrm{l})$ & $3.0 \pm 0.3$ & $3.0 \pm 0.5$ & $3.6 \pm 0.2$ & $3.4 \pm 0.7$ & $3.3 \pm 0.6$ \\
\hline $\operatorname{ALT}(\mu \mathrm{kat} / \mathrm{l})$ & $1.9 \pm 0.2$ & $1.7 \pm 0.5$ & $2.1 \pm 0.2$ & $2.0 \pm 0.4$ & $2.0 \pm 0.3$ \\
\hline KBWR (g/kg) & $15.3 \pm 0.6$ & $14.6 \pm 0.7$ & $20.0 \pm 1.3^{*}$ & $17.7 \pm 1.1$ & $15.7 \pm 0.7^{\dagger}$ \\
\hline $\mathrm{SCr}(\mu \mathrm{mol} / \mathrm{l})$ & $7.1 \pm 1.8$ & $6.2 \pm 2.6$ & $34.5 \pm 3.5^{*}$ & $22.9 \pm 1.8^{* \dagger}$ & $20.3 \pm 2.6^{* \dagger}$ \\
\hline $\mathrm{UAC}(\mu \mathrm{g} / \mu \mathrm{mol})$ & $8.2 \pm 0.6$ & $7.8 \pm 0.2$ & $24.4 \pm 1.5^{*}$ & $19.4 \pm 0.5^{* \dagger}$ & $13.9 \pm 1.2^{\dagger}$ \\
\hline Glomerular area $\left(\mu \mathrm{m}^{2}\right)$ & $2,188 \pm 165$ & $2,146 \pm 209$ & $3,949 \pm 264 *$ & $3,014 \pm 154^{* \dagger}$ & $2,555 \pm 182 *^{\dagger}$ \\
\hline $\mathrm{PAS}^{+}$mesangial area (\%) & $7.0 \pm 0.2$ & $7.4 \pm 0.1$ & $13.8 \pm 1.0^{*}$ & $10.0 \pm 0.4^{* \dagger}$ & $8.6 \pm 0.6^{* \dagger}$ \\
\hline
\end{tabular}

Results reported as means \pm SEM (number of animals), and were analysed by two-way ANOVA followed by Bonferroni's post hoc test

${ }^{*} p<0.05$ vs non-diabetic + vehicle; ${ }^{\dagger} p<0.05$ vs diabetic + vehicle

ALT, alanine aminotransferase; AST, aspartate aminotransferase; BG, mean blood glucose; $\Delta \mathrm{BW}$, body weight change; Chol, cholesterol; KBWR, kidney-to-body weight ratio; ND, not determined; SCr, serum creatinine; TG, triacylglycerol; UAC, urine albumin-to-creatinine ratio
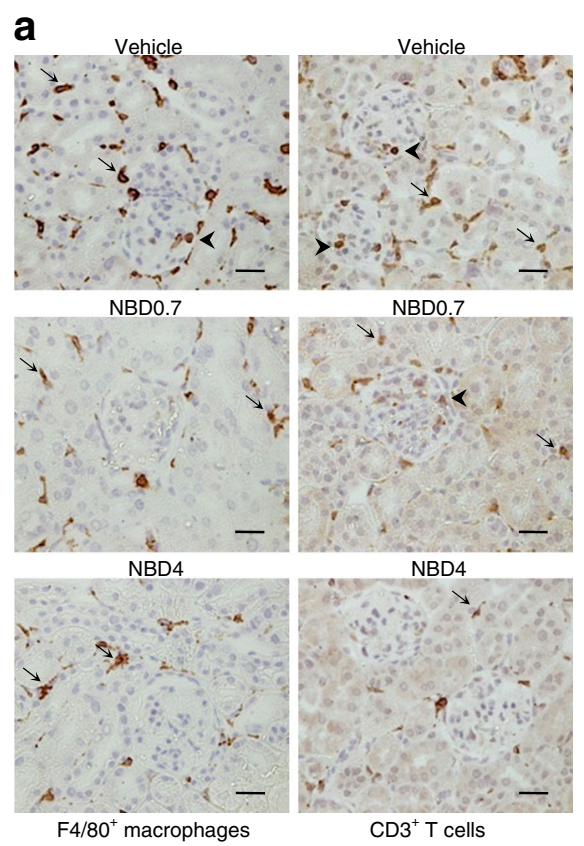

Fig. 4 Anti-inflammatory effects of NBD peptide on diabetic kidneys. (a-c) Leucocyte immunodetection in renal sections from diabetic mice treated with vehicle and two doses of peptide (NBD0.7 and NBD4 for 0.7 and $4 \mu \mathrm{mol} / \mathrm{kg}$, respectively). (a) Representative micrographs (scale bar, $20 \mu \mathrm{m}$ ) showing infiltrating cells in glomeruli (arrowheads) and interstitium (arrows). Quantification of infiltrating cells in glomeruli (b) and b
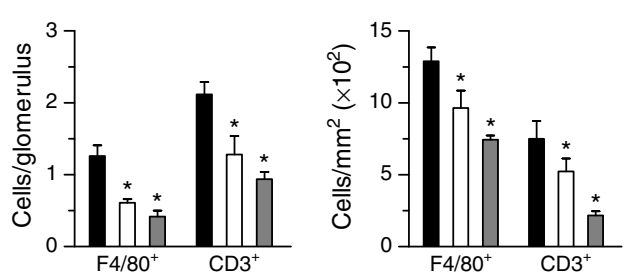

d

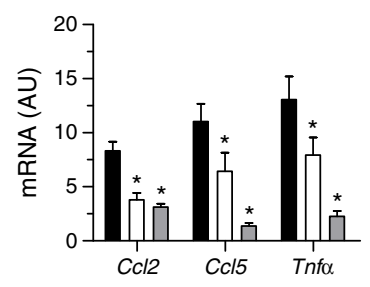

interstitium (c). (d) Real-time PCR analysis in renal cortex from diabetic mice. Normalised values are expressed in arbitrary units (AU). Data are means \pm SEM. Black bars indicate diabetic + vehicle $(n=9)$; white bars, diabetic+NBD0.7 $(n=7)$; grey bars, diabetic+NBD4 $(n=9) .{ }^{*} p<0.05$ vs diabetic+vehicle 
Fig. 5 NBD therapy alters the size and composition of atherosclerotic plaques in diabetic mice. (a, b) Representative Oil Red O/haematoxylin staining (a) and lesion area measurement (b) in aortic root sections from diabetic mice treated with vehicle (black circles) and NBD peptide (NBD0.7, white triangles; NBD4, grey triangles). (c) Lipid content (Oil Red $\mathrm{O}$ area) in plaques. (d) Representative micrographs and quantification of macrophages and $\mathrm{T}$ lymphocytes in diabetic mouse aortas. (e) Representative images showing higher collagen (picrosirius red) and VSMC $(\alpha$-actin) content in NBD-treated mice. The histogram shows the ratios of collagen/lipid (picrosirius red/Oil Red O) and VSMC/macrophage ( $\alpha$-actin/ MOMA-2). Data are means \pm SEM. Black bars indicate diabetic + vehicle $(n=9)$; white bars, diabetic+NBD0.7 $(n=7)$; grey bars, diabetic+NBD4 $(n=9)$. ${ }^{*} p<0.05$ vs diabetic + vehicle. Scale bar: $50 \mu \mathrm{m}$ (a, e), $40 \mu \mathrm{m}$ (d). Arrows, positive staining; L, lumen; dashed lines, atheroma plaque a
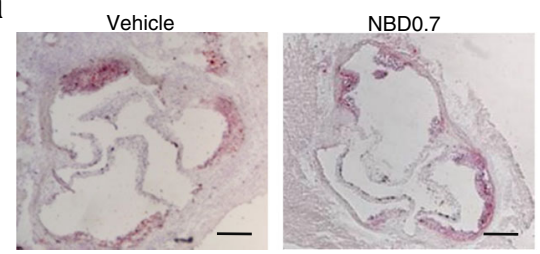

b

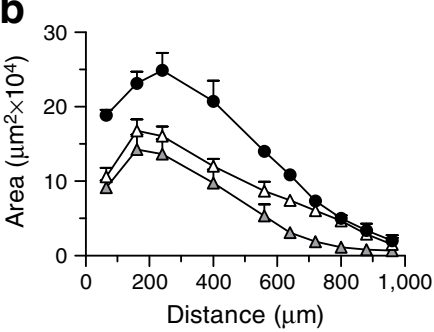

d

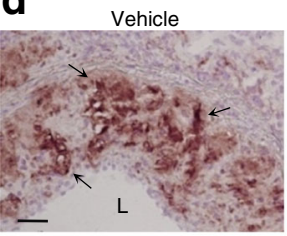

NBD0.7
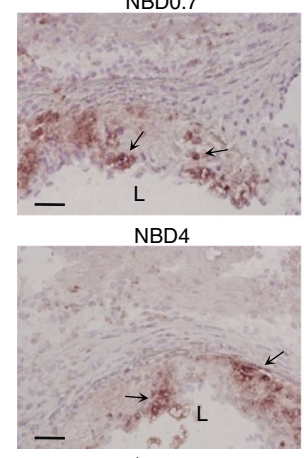

MOMA-2 $2^{+}$macrophages

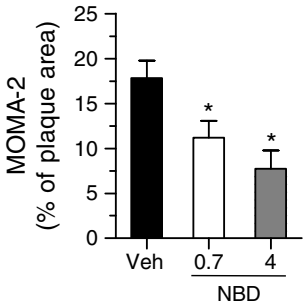

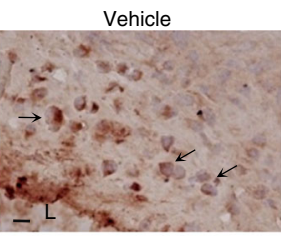

NBD0.7

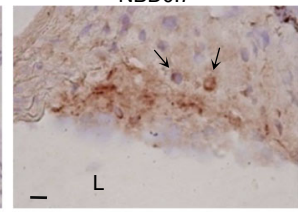

NBD4
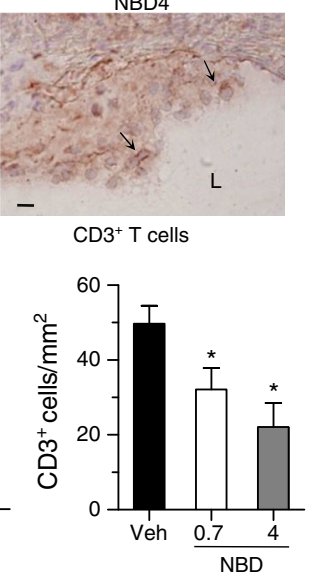

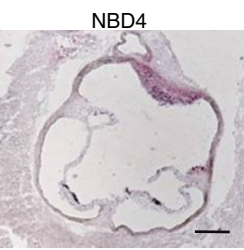

C

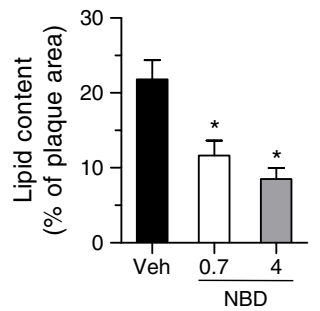

e
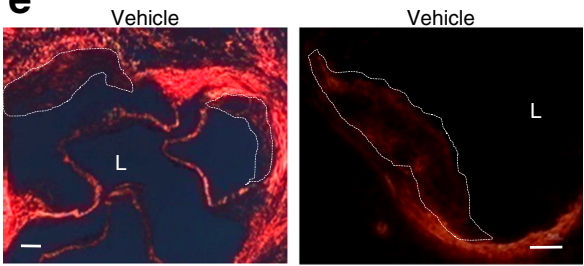

NBD4

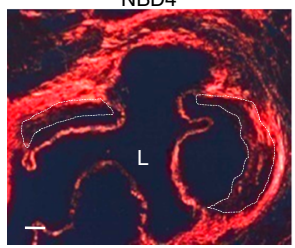

Picrosirius red
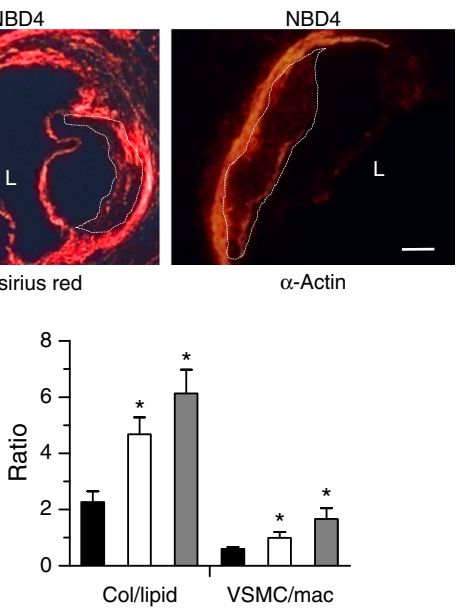

key pathogenic mechanisms and intracellular pathways leading to progression of diabetes complications are not modified by the current therapies $[11,20]$. Herein, we report that a cellpermeable peptide derived from the IKK $\alpha / \beta N B D$ domain inhibits the canonical NF- $\mathrm{KB}$ pathway and ameliorates renal dysfunction and atherosclerosis in diabetic mice primarily through the attenuation of local and systemic inflammation.

Dysregulated NF- $\mathrm{KB}$ activation contributes to many immune-inflammatory diseases, including diabetes [6-9]. $\mathrm{NF}-\mathrm{KB}$ gene polymorphisms influence the susceptibility to type 1 and 2 diabetes and affect microvascular and atherosclerotic complications in patients [13, 28, 29]. Hyperglycaemia, dyslipidaemia, oxidative stress and inflammation can also lead to the occurrence of diabetes complications by activating canonical NF- $\mathrm{KB}$-driven genes [15]. Studies in animal models with either total or cell-specific in-

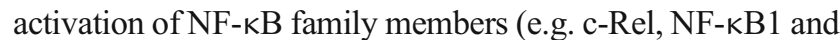
NEMO) further implicate NF-KB in diabetes [30-32]. Moreover, anti-inflammatory compounds exhibit an ameliorating effect on diabetic symptoms and long-term complications by directly inhibiting IKK activity [33, 34], although limitations due to cellular toxicity and immunosuppression 
a

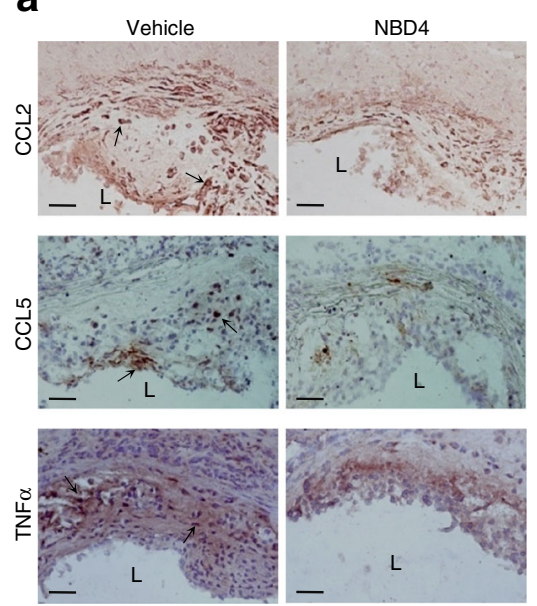

Fig. 6 NBD reduces plaque and systemic inflammation in diabetic mice (a, b) Representative micrographs (a; arrows, positive staining; L, lumen; scale bar, $40 \mu \mathrm{m}$ ) and quantification (b) of CCL2, CCL5 and TNF $\alpha$ expression in diabetic mouse aortas. (c, d) Real-time PCR analysis in

have prompted a search for alternative strategies [19]. Our results in an experimental model of combined hyperglycaemia and hyperlipidaemia (diabetic $\mathrm{Apoe}^{-/-}$mice) demonstrate that NF- $\mathrm{KB}$ activation status in kidney and aorta highly correlates with the severity of nephropathy and atherosclerosis, thus confirming the key role of the NF- $\mathrm{kB}$ inflammatory pathway in the pathogenesis of diabetic complications. We also provide in vivo and in vitro evidence that peptide-based inhibition of IKK complex formation may be an alternative strategy to suppress NF-KB-mediated inflammation in diabetes. In renal and vascular cells cultured under hyperglycaemic and inflammatory conditions, we demonstrate that NBD peptide, but not the mutated sequence, disrupted the interaction of IKK $\alpha / \beta$ with NEMO, therefore preventing short-term IKK activation, p65 nuclear translocation, and NF-kB-driven gene expression. b c
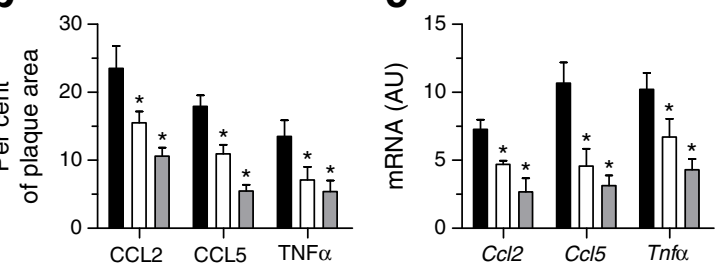

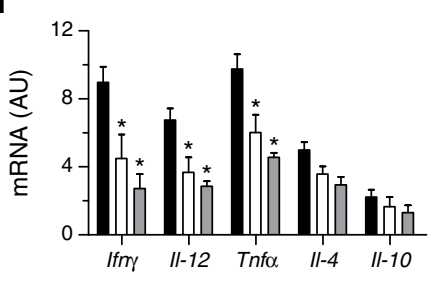

aorta (c) and spleen (d). Normalised values are expressed in arbitrary units (AU). Data are means \pm SEM. Black bars indicate diabetic + vehicle $(n=9)$; white bars, diabetic+NBD0.7 $(n=7)$; grey bars, diabetic+NBD4 $(n=9) .{ }^{*} p<0.05$ vs diabetic + vehicle

These findings are consistent with those of previous studies characterising the in vitro NF- $\mathrm{kB}$ blocking effect of different NBD peptide sequences in cytokine-stimulated mononuclear cells, osteoclasts and fibroblasts [26, 35-38]. Remarkably, NBD peptide reversed the cellular responses induced by long-term exposure to $\mathrm{HG}$, but did not influence either NF-KB or cell viability under normoglycaemic conditions. Hence, the primary role of NF- $\mathrm{kB}$ in normal cellular functions is preserved, resulting in less toxicity, which represents an advance over other NF-kB inhibitors [18, 19, 35].

Our results constitute the first in vivo characterisation of the nephroprotective effect of NBD peptide. Indeed, NBD therapy did not affect the metabolic severity of diabetes, as evidenced by no changes in hyperglycaemia, lipid profile and body weight. Interestingly, we found good tissue distribution,

Fig. 7 Attenuated NF-kB activity in diabetic mice by NBD therapy. (a) In situ localisation of activated NF- $\mathrm{KB}$ in kidneys and atheroma plaques of diabetic mice (arrows, positive staining; L, lumen; scale bar, $20 \mu \mathrm{m}$ ). Analysis of NF- $\mathrm{KB}^{+}$cells in glomeruli (b), tubulointerstitium (c) and atherosclerotic lesions (d) Means \pm SEM $(n=7-9$ mice/group). ${ }^{*} p<0.05$ vs diabetic + vehicle a
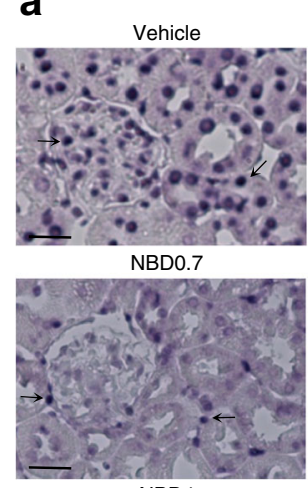

NBD4
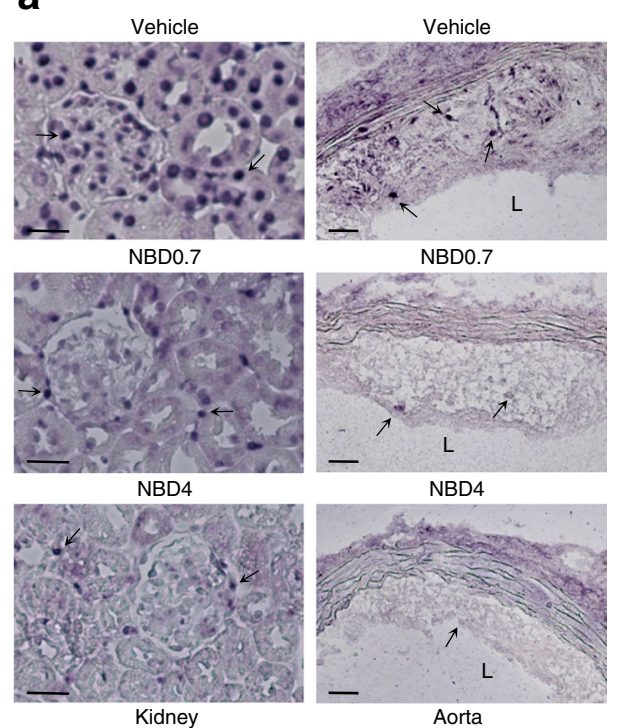

b

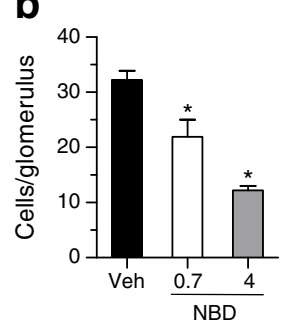

d

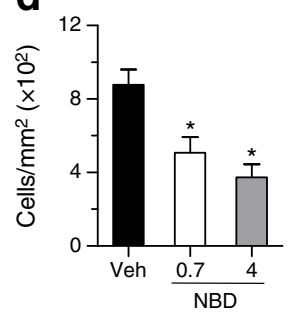

C

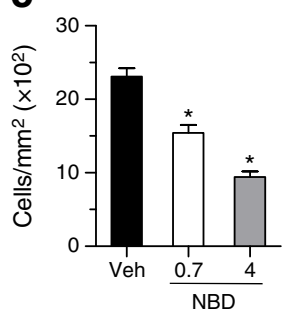


effective anti-inflammatory action and renal histological improvement without any observable toxicity, liver damage or other detrimental side effects. Moreover, kidneys from NBDtreated mice displayed less intranuclear NF- $\mathrm{KB}$ activity and NF- $\kappa B$-regulated gene expression, along with an attenuation of diabetes-induced structural and functional abnormalities. These results are comparable to those reported with different cell-permeable NBD versions in animal models of acute inflammation [10, 39], arthritis [38], inflammatory bowel disease [35], lung inflammation [40], muscular dystrophy [41], B cell lymphoma [42] and neuroinflammation [37].

Excessive production of cytokines is important in the pathogenesis of diabetic nephropathy, and cell proliferation and fibrosis are the major contributors to diabetes-induced renal pathological changes. Moreover, hyperglycaemia upregulates inflammatory gene expression and hastens the recruitment of leucocytes $[16,17,21]$, which further contribute to diabetic renal injury, either by direct interaction with mesangial and tubular cells or by releasing pro-inflammatory and pro-fibrotic mediators $[4,5]$. Our work demonstrates that NBD peptide administration in diabetic mice improves renal function variables (creatinine and albumin-to-creatinine ratio) and glomerular lesions (leucocyte infiltration, hypertrophy, mesangial expansion and glomerulosclerosis). NBD also protected from the development of tubular atrophy and interstitial fibrosis and inflammation, hallmarks of end-stage renal failure. These observations, in conjunction with reduced expression of chemokines, cytokines, growth factors and extracellular matrix proteins suggest that NBD peptide effectively attenuates renal inflammation and fibrosis, two key mechanisms for diabetic renal disease. Therefore, our findings indicate that the NF-KB pathway is a potential upstream target for the development of therapeutic agents in diabetic nephropathy.

$\mathrm{NF}-\mathrm{KB}$ is a crucial pro-atherogenic factor that regulates gene expression involved in all phases of the atherosclerosis process, from early fatty streak formation and advanced plaque progression to thrombotic complications [15, 43]. Several compounds targeting main steps in the NF- $\mathrm{BB}$ signalling pathway (e.g. IKK activation, IKB phosphorylation, ubiquitin-proteasome system, nuclear translocation and DNA binding) have been reported to ameliorate atherosclerosis in experimental models $[43,44]$. We have provided in vivo evidence that NBD peptide dose-dependently attenuates $\mathrm{NF}-\mathrm{KB}$ activation in the aorta and limits atheroma plaque formation in type 1 diabetic Apoe $e^{-/-}$mice. This finding is in agreement with that of a recently published report showing that NBD improved vascular dysfunction (in terms of myogenic tone and endothelium-dependent relaxation) in coronary and mesenteric resistance arteries from a mouse model of type 2 diabetes [45]. Importantly, we observed that NF-кB inhibition altered plaque composition and inflammation in mouse atherosclerotic lesions without affecting serum lipid levels. In fact, the decrease in atheroma size correlated with reduced numbers of macrophages and $\mathrm{T}$ cells within the lesions of diabetic mice and reduced aortic expression of proinflammatory factors (CCL2, CCL5 and TNF $\alpha$ ) involved in migration and activation of vascular cells. Atheroprotection by NBD peptide also resulted in the development of a more stable plaque phenotype characterised by higher collagen:lipid and VSMC:macrophage ratios than those in untreated diabetic mice. Considering that most acute clinical events of atherosclerosis, such as myocardial infarction and stroke, are caused by the rupture of an unstable (leucocyte- and lipid-rich, collagen-poor) plaque [46], efficient strategies to modulate harmful NF-KB-mediated cell responses by directly targeting IKK could be of benefit in slowing lesion progression.

Besides a local anti-inflammatory effect on mouse kidney and aorta, we also detected an indirect action of NBD on systemic inflammation, as evidenced by reduced splenic expression of pro-inflammatory Th1 cytokines, but not antiinflammatory Th2 genes. It is well recognised that NF- $\mathrm{KB}$ transcriptional activity directly controls the main cytokine drivers of the Th1 response [7, 47]. Furthermore, elevated levels of Th1 cytokines correlate with proteinuria [48] and the risk of cardiovascular complications [49] in patients with type 2 diabetes. Consistent with this, our findings indicate that regulation of the systemic Th1-mediated immunoinflammatory response may account, at least in part, for the in vivo protective effect of NBD in diabetic mice.

In conclusion, our results demonstrate that NBD peptide potently inhibits NF- $\mathrm{kB}$-mediated inflammatory responses in diabetic mice, thereby preventing the progression of diabetesassociated nephropathy and atherosclerosis. Given the pivotal role of NF- $\mathrm{KB}$ activation in diabetes development, we suggest selective inhibition of the IKK-dependent canonical NF- $\mathrm{BB}$ pathway as a feasible approach against diabetes inflammatory complications.

Acknowledgements The authors thank J.L. Martin-Ventura and L.M. Blanco-Colio (Nephrology Department, IIS-Fundacion Jimenez Diaz, Madrid, Spain) for material and intellectual support, and M. Gonzalez (IIS-Fundacion Jimenez Diaz, Madrid, Spain) for technical assistance with the confocal microscope.

Funding This work was supported by grants from the Spanish Ministry of Economy and Competitiveness (SAF2012-38830), the Spanish Ministry of Health (Fondo de Investigaciones Sanitarias; PI14/00386, PIE13/00051), the European Commission (FP7-HEALTH-2013INNOVATION-1-602422), Iñigo Alvarez de Toledo Renal Foundation, and the Spanish Societies of Nephrology and Arteriosclerosis.

Duality of interest The authors declare that there is no duality of interest associated with this manuscript.

Contribution statement AO, CR and IL contributed to study design, data acquisition and analysis, and drafted the manuscript. BM, JB and JE contributed to conception and design, data analysis, and reviewed the manuscript for intellectual content. CGG obtained funding, conceived and designed the study, analysed the data and wrote the manuscript. All 
authors have approved the final version. CGG is the guarantor of this work.

\section{References}

1. Nathan DM (1993) Long-term complications of diabetes mellitus. N Engl J Med 328:1676-1685

2. De CS, Bacci S, Piras GP et al (1997) High prevalence of risk factors for cardiovascular disease in parents of IDDM patients with albuminuria. Diabetologia 40:1191-1196

3. Rask-Madsen C, King GL (2013) Vascular complications of diabetes: mechanisms of injury and protective factors. Cell Metab 17:20 33

4. Williams MD, Nadler JL (2007) Inflammatory mechanisms of diabetic complications. Curr Diab Rep 7:242-248

5. Nilsson J, Bengtsson E, Fredrikson GN, Bjorkbacka H (2008) Inflammation and immunity in diabetic vascular complications. Curr Opin Lipidol 19:519-524

6. Beinke S, Ley SC (2004) Functions of NF-kappaB1 and NF-kappaB2 in immune cell biology. Biochem J 382:393-409

7. Hayden MS, Ghosh S (2011) NF-kB in immunobiology. Cell Res 21:223-244

8. Hacker H, Karin M (2006) Regulation and function of IKK and IKK-related kinases. Sci STKE 2006:re13

9. Hinz M, Scheidereit C (2014) The IкB kinase complex in NF-kappaB regulation and beyond. EMBO Rep 15:46-61

10. May MJ, D'Acquisto F, Madge LA, Glockner J, Pober JS, Ghosh S (2000) Selective inhibition of NF-kappaB activation by a peptide that blocks the interaction of NEMO with the IKB kinase complex. Science 289:1550-1554

11. Brosius FC, Khoury CC, Buller CL, Chen S (2010) Abnormalities in signaling pathways in diabetic nephropathy. Expert Rev Endocrinol Metab 5:51-64

12. Mezzano S, Aros C, Droguett A et al (2004) NF-kappaB activation and overexpression of regulated genes in human diabetic nephropathy. Nephrol Dial Transplant 19:2505-2512

13. Schmid H, Boucherot A, Yasuda Y et al (2006) Modular activation of nuclear factor-kappaB transcriptional programs in human diabetic nephropathy. Diabetes 55:2993-3003

14. Yi B, Hu X, Zhang H et al (2014) Nuclear NF-kappaB p65 in peripheral blood mononuclear cells correlates with urinary MCP-1, RANTES and the severity of type 2 diabetic nephropathy. PLoS One 9:e99633

15. Baker RG, Hayden MS, Ghosh S (2011) NF-kappaB, inflammation, and metabolic disease. Cell Metab 13:11-22

16. Ha H, Yu MR, Choi YJ, Kitamura M, Lee HB (2002) Role of high glucose-induced nuclear factor-kappaB activation in monocyte chemoattractant protein-1 expression by mesangial cells. J Am Soc Nephrol 13:894-902

17. Gao P, Wu X, Shui H, Jia R (2013) Fluvastatin inhibits high glucose-induced nuclear factor kappa B activation in renal tubular epithelial cells. J Nephrol 26:289-296

18. Gupta SC, Sundaram C, Reuter S, Aggarwal BB (2010) Inhibiting NF-kappaB activation by small molecules as a therapeutic strategy. Biochim Biophys Acta 1799:775-787

19. Gamble C, McIntosh K, Scott R, Ho KH, Plevin R, Paul A (2012) Inhibitory kappa $\mathrm{B}$ Kinases as targets for pharmacological regulation. Br J Pharmacol 165:802-819

20. Fernandez-Fernandez B, Ortiz A, Gomez-Guerrero C, Egido J (2014) Therapeutic approaches to diabetic nephropathy - beyond the RAS. Nat Rev Nephrol 10:325-346
21. Lopez-Parra V, Mallavia B, Lopez-Franco O et al (2012) $\mathrm{Fc} \gamma$ receptor deficiency attenuates diabetic nephropathy. J Am Soc Nephrol 23:1518-1527

22. Hernandez-Vargas P, Lopez-Franco O, Sanjuan G et al (2005) Suppressors of cytokine signaling regulate angiotensin IIactivated Janus kinase-signal transducers and activators of transcription pathway in renal cells. J Am Soc Nephrol 16:1673-1683

23. Lopez-Franco O, Hernandez-Vargas P, Ortiz-Munoz G et al (2006) Parthenolide modulates the NF-kappaB-mediated inflammatory responses in experimental atherosclerosis. Arterioscler Thromb Vasc Biol 26:1864-1870

24. Recio C, Oguiza A, Lazaro I, Mallavia B, Egido J, Gomez-Guerrero C (2014) Suppressor of cytokine signaling 1-derived peptide inhibits janus kinase/signal transducers and activators of transcription pathway and improves inflammation and atherosclerosis in diabetic mice. Arterioscler Thromb Vasc Biol 34:1953-1960

25. Lopez-Franco O, Suzuki Y, Sanjuan G et al (2002) Nuclear factorkappa B inhibitors as potential novel anti-inflammatory agents for the treatment of immune glomerulonephritis. Am J Pathol 161: $1497-1505$

26. Baima ET, Guzova JA, Mathialagan S et al (2010) Novel insights into the cellular mechanisms of the anti-inflammatory effects of NFkappaB essential modulator binding domain peptides. J Biol Chem 285:13498-13506

27. Lassila M, Seah KK, Allen TJ et al (2004) Accelerated nephropathy in diabetic apolipoprotein e-knockout mouse: role of advanced glycation end products. J Am Soc Nephrol 15:2125-2138

28. Hegazy DM, O'Reilly DA, Yang BM, Hodgkinson AD, Millward BA, Demaine AG (2001) NFKB polymorphisms and susceptibility to type 1 diabetes. Genes Immun 2:304-308

29. Romzova M, Hohenadel D, Kolostova K et al (2006) NFkappaB and its inhibitor IKB in relation to type 2 diabetes and its microvascular and atherosclerotic complications. Hum Immunol 67:706713

30. Lamhamedi-Cherradi SE, Zheng S, Hilliard BA et al (2003) Transcriptional regulation of type I diabetes by NF-kappa B. J Immunol 171:4886-4892

31. Eldor R, Yeffet A, Baum K et al (2006) Conditional and specific NF-kappaB blockade protects pancreatic beta cells from diabetogenic agents. Proc Natl Acad Sci U S A 103:5072-5077

32. Wunderlich FT, Luedde T, Singer S et al (2008) Hepatic NF-kappa B essential modulator deficiency prevents obesity-induced insulin resistance but synergizes with high-fat feeding in tumorigenesis. Proc Natl Acad Sci U S A 105:1297-1302

33. Kumar A, Negi G, Sharma SS (2012) Suppression of NF-kappaB and NF-kappaB regulated oxidative stress and neuroinflammation by BAY 11-7082 (IKB phosphorylation inhibitor) in experimental diabetic neuropathy. Biochimie 94:1158-1165

34. Huang H, Xin H, Liu X et al (2012) Novel anti-diabetic effect of SCM-198 via inhibiting the hepatic NF-kappaB pathway in $\mathrm{db} / \mathrm{db}$ mice. Biosci Rep 32:185-195

35. Dave SH, Tilstra JS, Matsuoka K et al (2007) Amelioration of chronic murine colitis by peptide-mediated transduction of the IKB kinase inhibitor NEMO binding domain peptide. J Immunol 179:7852-7859

36. Tas SW, de Jong EC, Hajji N et al (2005) Selective inhibition of NF-kappaB in dendritic cells by the NEMO-binding domain peptide blocks maturation and prevents $\mathrm{T}$ cell proliferation and polarization. Eur J Immunol 35:1164-1174

37. Dasgupta S, Jana M, Zhou Y, Fung YK, Ghosh S, Pahan K (2004) Antineuroinflammatory effect of NF-kappaB essential modifierbinding domain peptides in the adoptive transfer model of experimental allergic encephalomyelitis. J Immunol 173:1344-1354

38. Jimi E, Aoki K, Saito H et al (2004) Selective inhibition of NF-kappa B blocks osteoclastogenesis and prevents inflammatory bone destruction in vivo. Nat Med 10:617-624 
39. di Meglio P, Ianaro A, Ghosh S (2005) Amelioration of acute inflammation by systemic administration of a cell-permeable peptide inhibitor of NF-kappaB activation. Arthritis Rheum 52:951-958

40. Ankermann T, Reisner A, Wiemann T, Krams M, Kohler H, Krause MF (2005) Topical inhibition of nuclear factor-kappaB enhances reduction in lung edema by surfactant in a piglet model of airway lavage. Crit Care Med 33:1384-1391

41. Reay DP, Yang M, Watchko JF et al (2011) Systemic delivery of NEMO binding domain/IKK $\gamma$ inhibitory peptide to young $\mathrm{mdx}$ mice improves dystrophic skeletal muscle histopathology. Neurobiol Dis 43:598-608

42. Habineza NG, Gaurnier-Hausser A, Patel R et al (2014) A phase I clinical trial of systemically delivered NEMO binding domain peptide in dogs with spontaneous activated B cell like diffuse large B cell lymphoma. PLoS One 9:e95404

43. Pamukcu B, Lip GY, Shantsila E (2011) The nuclear factor-kappa B pathway in atherosclerosis: a potential therapeutic target for atherothrombotic vascular disease. Thromb Res 128:117-123
44. Gomez-Guerrero C, Mallavia B, Egido J (2012) Targeting inflammation in cardiovascular diseases. Still a neglected field? Cardiovasc Ther 30:e189-e197

45. Kassan M, Choi SK, Galan M et al (2013) Enhanced NF-kappaB activity impairs vascular function through PARP-1-, SP-1-, and COX-2-dependent mechanisms in type 2 diabetes. Diabetes 62 : 2078-2087

46. Halvorsen B, Otterdal K, Dahl TB et al (2008) Atherosclerotic plaque stability - what determines the fate of a plaque? Prog Cardiovasc Dis 51:183-194

47. Oh H, Ghosh $\mathrm{S}$ (2013) NF-kappaB: roles and regulation in different CD4(+) T cell subsets. Immunol Rev 252:41-51

48. Wu CC, Chen JS, Lu KC et al (2010) Aberrant cytokines/ chemokines production correlate with proteinuria in patients with overt diabetic nephropathy. Clin Chim Acta 411:700-704

49. Mahmoud F, Al-Ozairi E (2013) Inflammatory cytokines and the risk of cardiovascular complications in type 2 diabetes. Dis Markers 35:235-241 